\title{
Research On the Craniofacial Measurement Characteristics and Pollution Identification of Unearthed Human Bones at Shenna Ruins, China
}

Jiaxin Li

Shaanxi Normal University

Bingjie Mai

Shaanxi Normal University

Ying Zhang

Shaanxi Normal University

Liang Chen

Northwest University

Yuhu Li

Shaanxi Normal University

Juanli Wang

Shaanxi Normal University

Jing Cao ( $\nabla$ jingcao@snnu.edu.cn )

Shaanxi Normal University https://orcid.org/0000-0001-8249-2915

Research article

Keywords: Shenna ruins, unearthed human bones, contamination, craniofacial measurement

Posted Date: October 18th, 2021

DOI: https://doi.org/10.21203/rs.3.rs-955208/v1

License: (c) (1) This work is licensed under a Creative Commons Attribution 4.0 International License. Read Full License 


\section{Abstract}

The unearthed human bones are important materials for revealing ancient human food, ancient environment and ancient climate, and the origin of ancient humans, which the chemical composition and biological characteristics of bones have changed to varying degrees in the process of diagenesis, means that they were contaminated. Therefore, judging whether the unearthed ancient human bones are contaminated is a prerequisite for scientific analysis, environmental archaeology, and research on ancient human recipes. This paper is mainly using traditional morphological methods to analyze and study the craniofacial measurement characteristics of the unearthed human bones at the Shenna ruins, and the contamination of the unearthed human bones by burial environment and diagenesis was judged by using pH measurement, Scanning Electrion Microscopy-Energy Dispersive Spectrometer (SEM-EDS), X-ray Diffraction (XRD), and Fourier transform red external light spectrum (FTIR). The results show that the organic composition of the remains at Shenna ruins is decomposed in a large amount, the inorganic structure is destroyed, which will eventually cause looseness and porosity. However, the composition of inorganic minerals of the human bones has not been changed or contaminated, they could be avoided unnecessary waste of energy and work and research bias in further study of paleoenvironment and paleoclimate in Shenna ruins.

\section{Introduction}

The hard tissues of ancient humans, that is, unearthed human bones are important materials for revealing ancient human food ${ }^{[1,2]}$, ancient environment and ancient climate, and the origin of ancient humans. Through scientific analysis of their chemical composition, it is expected to reveal the recipes of ancient ancestors, reconstruct their way of life, explore the ancient environment and human migration activities.

For the large number of ancient human hard tissues unearthed, the bioarchaeology is mostly based on morphological methods ${ }^{[3-5]}$, from the perspective of physical anthropology, through the comparison of the characteristics of human hard tissues, the archaeologists can conduct analysis and research on racial discrimination and pathology; or by extracting trace elements from unearthed human bones, the archaeologists can conduct scientific analysis to reveal the rich potential information contained in ancient human bones.

However, the analysis of the ancient human bones unearthed is based on an important assumption that after a long burial time after death, the bones still retain the original chemical composition and biological characteristics. Nevertheless, due to the long-term burial of the unearthed human bones, the geological environment, soil, temperature, humidity, groundwater and other factors during the long-term burial process ${ }^{[6]}$ have caused the isotope ratio and trace elements of the bones to change to varying degrees, and this process is also called as the bone diagenesis ${ }^{[7-9]}$. In other words, the chemical composition and biological characteristics of bones have changed to varying degrees in the process of diagenesis, which means they were contaminated. Therefore, judging whether the unearthed ancient human bones are 
contaminated is a prerequisite for scientific analysis ${ }^{[10]}$, environmental archaeology, and research on ancient human recipes.

This paper is mainly based on the two human bones unearthed at the Shenna ruins as the research object, using traditional morphological methods to analyze and study the craniofacial measurement characteristics of the unearthed human bones, and to identify the pollution and degree of the human bone samples extracted, in order to research whether they can be used in the scientific analysis of trace elements ${ }^{[11]}$. It hopes to reveal the richer hidden information contained in the ancient human bones, and provide scientific basis for exploring the recipes of the ancestors at the Shenna site and their ethnic research.

\section{Overview Of The Shenna Ruins}

The Shenna ruin is located in the north of Xiaoqiao Village, Chengbei District, Xining City, Qinghai Province. In 2006, the State Council announced it as the sixth batch of national key cultural relics protection units. The ruin is located on a secondary terrace at the intersection of Huangshui and its tributary Beichuan River. The terrace is narrow from east to west and long from north to south. It is a long strip with low south and high north, covering an area of about 100,000 square meters. Its archaeological value is firstly manifested in that it was a hub on the corridor of cultural exchange between the Hexi Corridor and the Western Regions 4000 years ago, and the communication function of this route during the Qijia cultural period was the main road for the spread of Eastern and Western culture in that period; secondly, the Qijia culture where the Shenna ruin is located is an era of transformation and revolution, mainly based on Qijia culture, with a small amount of Majiayao type, Banshan type and Kayue culture, therefore, it is a representative settlement in this era of transformation and revolution. In 1992 and 2016, the Qinghai Provincial Institute of Cultural Relics and Archaeology conducted archaeological exploration and excavation of 2000 square meters of it, and the excavated area was 2 meters thick, and discovered 171 houses, 358 ash pits, and 19 tombs, it is the site of a Qiang settlement about 3500 years ago, and the relics are very rich. Therefore, the archaeological research of the Shenna ruins is of high value for understanding and researching the cultural exchanges between the East and the West during the transition from the Neolithic to the Bronze Age, the lifestyles of the ancestors in the Northwest, and the ethnographic research.

\section{Samples And Pretreatment 2.1. Bone Samples}

In order not to affect the extraction and subsequent protection of archaeological information to the greatest extent, the remains fragments that do not affect the main original appearance of the cultural relics are selected as much as possible. The remains fragments and the soil samples were taken from the bottom of and around the burial pits at the Shenna ruins remains. In addition, the pig bones purchased in the market were used as a comparison sample, and the excess meat and skin on the pig bones were 
removed and rinsed with ultrapure water for later use. After exhumation the bones were stored in sealed in plastic bags at $4^{\circ} \mathrm{C}$ prior to analysis.

\subsection{Pretreatment of the Samples}

The remains are soak in ultra-pure water and repeatedly clean with ultrasonic until the soaked solution is colorless. Then soak in $5 \%$ acetic acid solution and continue ultrasonic cleaning for 10 minutes, discard the waste liquid, and continue to soak in $5 \%$ acetic acid solution for at least 15 hours. Finally, rinse with ultrapure water, ash at $725^{\circ} \mathrm{C}$ for 8 hours, cool and dry, and grind into powder.

After the meat, cortex and bone marrow are removed from the pig bones ${ }^{[12,13]}$, repeated ultrasonic cleaning is continued to remove impurities. After soaking for several hours in ultrapure water, it is dried at $80^{\circ} \mathrm{C}$ for at least 10 hours. One part of the pretreated pig bone was ground into powder for use, and the other part was also calcined at $725^{\circ} \mathrm{C}$ for 8 hours, cooled and dried, and then ground into powder for use. After exhumation the bones were stored in sealed in plastic bags at $4^{\circ} \mathrm{C}$ prior to analysis.

\section{Experimental Methods}

\subsection{Analysis of Craniofacial Morphology of Unearthed Skulls}

The gender identification of unearthed human bones, as well as the observation and measurement of craniofacial morphological characteristics ${ }^{[14,15]}$, refer to the standards and methods of Shao Xiangqing and Zhu Hong. The germline purity test of skull measurement traits uses the comparison method of skull length, skull width, and skull index standard deviation: the standard difference of skull length, skull width and skull index in the skull group at the Shenna ruins is calculated and Pearson K and Morant GW assume that to compare the standard deviation of skull length, skull width and skull index in 2 groups of the same species.

\subsection{Characterization and Identification of the Skeletal Diagenesis}

\subsection{1 pH Measurement}

The $\mathrm{pH}$ values of the soil are measured according to the regulations in the national standard "Determination of soil pH NY/T 1377-2007", the distilled water was heated and boiled for 10 minutes, and sealed with plastic wrap for later use. $10.0 \mathrm{~g} \pm 0.1 \mathrm{~g}$ of soil was added to $25 \mathrm{~mL}$ boiling water, sealed and stirred for 5 minutes, and stood for 1-3 hours. Finally, after the supernatant was filtered with a Buchner funnel, the $\mathrm{pH}$ of each solution was tested using a pH meter (Sartorius PB-10, Sartorius Scientific Instruments Co., Ltd.). 


\subsubsection{Scanning Electronic Microscopy (SEM-EDS)}

The micromorphology of the surface of untreated and treated sample and char residues were observed by a Hitachi SU3500 scanning electron micro-scope (SEM) with a conductive gold coating under a voltage of $10 \mathrm{KV}$. The equipped energy dispersive spectrometry (EDS) was used to analyze the elements.

\subsubsection{X-ray Diffraction (XRD)}

The samples of human bone and site soil were investigated by X-ray diffractiometry (XRD, DX-2700, Dandong Haoyuan Instrument Co., Ltd). The X-ray emission was the Cu K-alpha line operating at $40 \mathrm{kV}$ and $30 \mathrm{~mA}$. The scan ranges from 5-80, with the step interval of 0.05 .

\subsubsection{Fourier transform red external light spectrum (FTIR)}

Fourier transform red external light spectrum (FTIR) can reflect the composition and structural characteristics of material. In this paper, FTIR technology was used to study the infrared spectral characteristics of bone to determine the composition and structure of bone, using an infrared spectrometer (PE-Frontier, PE company) in the wavelength range of $400 \sim 4000 \mathrm{~cm}^{-1}$.

The untreated samples were tested by SEM-EDS, and XRD and FTIR were used to analyze and compare the composition before and after ashing.

\section{Result And Discussion}

\subsection{Observation results of skull morphology}

As shown in Fig. 2, the skull and facial bone of RG1 were incomplete, only part of the left facial bone was seen, the skull bone was relatively intact, and the mandible was intact. The facial bone of RG2 on the right side of the skull is mutilated, the skull is relatively intact, and the mandible is intact. 
Table 1

The main index of the skull

\begin{tabular}{|c|c|c|c|c|c|}
\hline \multirow{2}{*}{\multicolumn{2}{|c|}{ Items }} & \multicolumn{2}{|l|}{ RG1 } & \multicolumn{2}{|l|}{ RG2 } \\
\hline & & Index & Type & Index & Type \\
\hline \multicolumn{2}{|l|}{ Cranial index } & 75.5 & Mid-cranial & 70.4 & Long skull \\
\hline \multicolumn{2}{|c|}{ Cranial height index } & 74.1 & Ortho-cranial & 77.2 & Tall skull \\
\hline \multicolumn{2}{|c|}{ Cranial width and height index } & 98.1 & Narrow skull & 109.6 & Narrow skull \\
\hline \multicolumn{2}{|l|}{ Forehead width } & 66.3 & Mid-forehead & 69.8 & Generous \\
\hline \multicolumn{2}{|c|}{ Foramen magnum index } & 90.4 & Generous & - & - \\
\hline \multicolumn{2}{|l|}{ Upper index } & - & - & - & - \\
\hline \multirow[t]{2}{*}{ 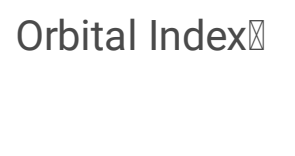 } & Left & 83.8 & Mid-orbit & - & - \\
\hline & Right & - & - & 82.6 & Mid-orbit \\
\hline \multirow[t]{2}{*}{ Orbital Index $\rrbracket$} & Left & 85.5 & Mid-orbit & - & - \\
\hline & Right & - & - & 89.9 & High orbit \\
\hline \multicolumn{2}{|l|}{ Nose index } & 47.4 & Mid-nose & - & \\
\hline \multicolumn{2}{|l|}{ Palatal index } & 85.4 & Broad palate & - & \\
\hline \multicolumn{2}{|c|}{ Facial protrusion index } & - & - & Orthognathic & Iathic \\
\hline
\end{tabular}


Table 2

Non-measured characteristics of the skull at Shenna ruins

\begin{tabular}{|c|c|c|c|}
\hline \multicolumn{2}{|c|}{ Observation items } & RG1 & RG2 \\
\hline \multicolumn{2}{|l|}{ Cranial shape } & Oval & Oval \\
\hline \multicolumn{2}{|c|}{ Eyebrow protrusion } & Medium & Weak \\
\hline \multicolumn{2}{|c|}{ Eyebrow bow range } & $<1 / 2$ & $<1 / 2$ \\
\hline \multicolumn{2}{|l|}{ Forehead } & Medium & Medium \\
\hline \multirow[t]{4}{*}{ Cranial suture } & Bregma section & Deep wave & Zigzag wave \\
\hline & Top section & Deep wave & Zigzag wave \\
\hline & Top hole section & Microwave & Deep wave \\
\hline & Back section & Microwave & Zigzag wave \\
\hline \multicolumn{2}{|l|}{ Mastoid } & Small & Medium \\
\hline \multicolumn{2}{|l|}{ Carina } & Slightly obvious & Slightly obvious \\
\hline \multicolumn{2}{|l|}{ Orbital } & Square & - \\
\hline \multicolumn{2}{|c|}{ Pear-shaped hole } & Pear-shaped & Heart-shaped \\
\hline \multicolumn{2}{|c|}{ Lower edge of pear-shaped hole } & Anterior nasal fossa-shaped & Sharp \\
\hline \multicolumn{2}{|l|}{ Nasal spines } & Grade I & - \\
\hline \multicolumn{2}{|l|}{ Canine fossa } & Weak & Weak \\
\hline \multicolumn{2}{|c|}{ Nasal depression } & Shallow & Shallow \\
\hline \multicolumn{2}{|l|}{ Wing area } & Top butterfly-shaped & Top butterfly-shaped \\
\hline \multicolumn{2}{|l|}{ Nasal bridge } & - & Concave \\
\hline \multicolumn{2}{|l|}{ Nasal bone } & - & Type I \\
\hline \multicolumn{2}{|l|}{ Top hole } & No & All left and right \\
\hline \multicolumn{2}{|l|}{ Sagittal crest } & Weak & Medium \\
\hline \multicolumn{2}{|c|}{ Forehead seam } & No & No \\
\hline \multicolumn{2}{|l|}{ Palatine } & U type & V type \\
\hline \multicolumn{2}{|l|}{ Palate pillow } & Crest-shaped & - \\
\hline \multicolumn{2}{|l|}{ Chin type } & Pointed shape & Round shape \\
\hline \multicolumn{2}{|c|}{ Mandibular angle } & Eversion & Eversion \\
\hline \multicolumn{2}{|c|}{ Mental hole position } & P2 position & P2M1 position \\
\hline
\end{tabular}




\begin{tabular}{|lll|}
\hline Observation items & RG1 & RG2 \\
\hline Mandibular pillow & Small & - \\
\hline Lower jaw of rocking chair & Obviously rocking chair & Slightly rocking chair \\
\hline
\end{tabular}

The skull measurement data and Non-measured characteristics of the skull at Shenna ruins (Tab. 1, Tab. 2) show that the skull shape is mainly oval and elliptical, the eyebrow arch is underdeveloped, the orbital shape can be square and rectangular, the nasal spines are not obvious, the canine fossa is weak, the nasal root is shallow, the pear-shaped hole is eccentric, the pear shape lower edge of the shaped hole is sharp. The remaining two lower jaws are rocking chair type. The skull is long, moderately high, and obviously in narrow skull. The forehead width is mainly wide-headed and medium-forehead. The orbit is mainly of middle orbit type and low orbit type. The nose shape is moderate in width, mostly middle nose shape. The phylogenetic type should belong to the Mongolian race and have certain characteristics of East Asian race.

As shown in Fig. 3, the most of the measurement data and corresponding indicators fall within the Mongolian race variation range, but the skull width is smaller than the common variation range, and the skull width and height index is too large, and the RG1 and RG2 width and height index is greater than the variation range. The overall judgment should belong to the Mongolian race and have certain characteristics of East Asian race. The craniofacial characteristics of the residents of the Shenna site are consistent with the life characteristics of the time they lived in.

\subsection{The pH values of the burial environment}

Table 3

The $\mathrm{pH}$ value of the burial environment at ruins

\begin{tabular}{|lllll|}
\hline Sampling location & $\mathbf{p H}$ & & & Average value \\
\hline RG2 & 8.16 & 8.10 & 8.14 & 8.13 \\
\hline Around RG2 & 7.87 & 7.91 & 7.87 & 7.88 \\
\hline Southwest RG2 & 8.15 & 8.14 & 8.14 & 8.14 \\
\hline
\end{tabular}

Table 3 shows that the $\mathrm{pH}$ value of the remains and the burial environment at ruins ranges from 7.8 to 8.2, indicating that the bones at the Shenna ruins are stored in an alkaline environment for a long time and are not easy to preserve organic components, which has aggravated the corrosion of the remains. The studies have shown that $\mathrm{pH}$ value of the burial environment at the Shenna ruins is mostly neutral or alkaline, mainly result of that most of the soil contains $\mathrm{Ca}^{2+}$, which is consistent with the location of the Shenna ruins in the northwest of our country and its unique soil properties.

\subsection{Microstructure and composition}


By using modern pig bones instead of modern human bones as a comparison sample, the comparison of the microscopic morphologies of the remains and modern pig bones was observed by the Scanning Electronic Microscopy. The Fig. 2-a show the cross-sectional microscopic morphology of the remains [16], there are pores of different sizes. Compared with the pig bone where the pores of Fig. 4-b are filled with organic matter such as bone marrow and grease, only trabecular bone remains in the remains to maintain the structure. Due to the interaction of inorganic bone minerals and organic matrix in natural bones, natural bones have good mechanical properties such as pressure resistance and flexural resistance, while the organic components are almost invisible in the picture a, which is also one of the reasons for the decrease of the mechanical strength of the remains. Fig. 4-c shows the microscopic morphology of part of the pores are filled with some other materials, which is preliminarily guessed as under the migration of water and other effects the pores in the cancellous bone with a large adsorption area were filled with soil. Fig. 4-e shows that the trabecular bone is full of tiny pores, the inorganic matter in the remains is the destruction and organic matter are decomposed, and the bones are covered with holes of different sizes, unlike the dense and compact structure of pig bone in Fig. 4-f, which becomes loose and porous and are suitable filling pipes for groundwater and soil, etc., so as to further erode the bones, accelerate the process of fragility of the remains, and directly cause the phenomenon of crunching and powdering of the remains.

The energy dispersive spectrometry (EDS) analysis is performed on the soil samples and remains of buried human remains, and the test results are shown in Fig. 5, revealing the types and percentages of elements contained in the soil samples. The top three elements with the most content are oxygen, calcium and silicon elements with mass fractions of $39.6 \%, 30.37 \%$ and $15.44 \%$. It can be preliminarily inferred from the element types and contents that the main components of the soil at the Shenna ruins may contain quartz $\left(\mathrm{SiO}_{2}\right)$ and calcium carbonate $\left(\mathrm{CaCO}_{3}\right)$. As Fig. 5 shows that the main content of calcium, oxygen, silicon and phosphorus in human bones, which occupy $34.71 \%, 34.06 \%, 11.83 \%$ and $7.31 \%$ respectively, in addition, the calculated relative molar ratio of $\mathrm{Ca} / \mathrm{P}$ can be as high as 3.67 , which is inconsistent with the uncontaminated bone-like $\mathrm{Ca} / \mathrm{P}$ ratio studied in the literature. The content of calcium is much higher and is speculated that the much higher content of calcium is assumed to be mostly due to the high content of calcium carbonate in the soil of Shenna ruins.

The remains are mainly composed of biogenic hydroxyapatite. Hydroxyapatite in fresh bone is generally in a weak crystalline state. After burial, some amorphous hydroxyapatite will change into a crystalline structure through diagenesis, resulting in increased crystallinity. The structure and composition of apatite will change during burial and diagenesis. XRD analysis can provide a basis for determining whether the bones are contaminated and whether they can be used for further element analysis, as shown in Fig. 6-C, it shows the XRD spectrum peaks of the soil. From the corresponding PDF card information, it shows that the soil is mainly composed of quartz $\mathrm{SiO}_{2}$ and limestone $\mathrm{CaCO}_{3}$, which is consistent with the estimation of element composition and content data in EDS analysis, also explains the reason for the alkaline soil $\mathrm{pH}$. The content of $\mathrm{CaCO}_{3}$ in soil existence also provides strong data to prove the conjecture that the $\mathrm{Ca}$ element in the EDS test results on the surface of the remains is too high. Retrieving the remains before 
and after ashing through PDF card data, and as shown in Fig. 6-a, the characteristic peaks of calcium hydroxyphosphate $\left(\mathrm{Ca}_{10}\left(\mathrm{PO}_{4}\right) 6(\mathrm{OH})_{2}\right)$, while that of pig bones before and after ashing is $\left(\mathrm{Ca}_{10}\left(\mathrm{PO}_{4}\right) 5 \mathrm{CO}_{3}(\mathrm{OH})\right)$ the characteristic peak, and it is due to the frequent occurrence of $\mathrm{CO}_{3}{ }^{2-}$ to $\mathrm{PO}_{4}{ }^{3-}$ ion substitution phenomenon in organisms. The crystal structure of hydroxyapatite will not be destroyed by this substitution, and it is not in the scope of chemical pollution, so it belongs to normal substitution.

In the comparison of the X-ray Diffractiometry (XRD) of the remains and the pig bone samples before and after the ashing treatment, it shows that the half high width value of the XRD characteristic peaks is smaller than that of the unashed sample. The diffraction peaks of the sample after chemical treatment become stronger and sharper, indicating that ashing ${ }^{[17]}$ will not only burn off organic components, but also improve the crystallinity of hydroxyapatite, which changes in the phase and microstructure of hydroxyapatite can cause changes in hydroxyapatite, and ashing can eliminate this effect caused by the phase. The diffraction peaks of pig bones are severely broadened before ashing, that is, the crystallinity is poor, but the diffraction peaks after ashing treatment have obvious changes. After the remains are ashed, the intensity and sharpness of the XRD diffraction peaks have also been significantly improved. It also proves that the remains samples in this paper are not contaminated and can still be used for meaningful scientific research. At the same time, the characteristic peaks of hydroxyapatite in the XRD spectrum show strong and sharp signals, it can be further concluded that although the burial for thousands of years has a certain stimulating effect on the decomposition of organic matter in the bone sample, but the influence on the composition of inorganic substances is relatively weak.

In the infrared spectrum ${ }^{[18-25]}, 3576 \mathrm{~cm}^{-1}$ is the absorption vibration peak of $\mathrm{H}_{2} \mathrm{O}$, which appears in all, but the weaker in the $B$ and $D$ curves, may be due to the large amount of water evaporation caused by high temperature ashing, which is adsorbed to the air during the grinding process. The asymmetric

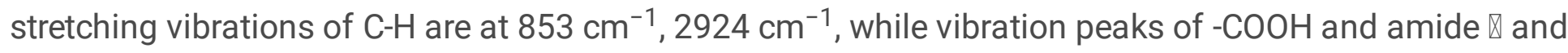
\appear at $1746 \mathrm{~cm}^{-1}$ and $1543 \mathrm{~cm}^{-1}, 1662 \mathrm{~cm}^{-1}$, respectively, these indicate that there are oil, bone marrow, protein and other substances in the pig bone, but they do not appear after ashing, the high temperature burns out the organic components in the bone during the ashing process. In addtion, the relatively weak vibration peaks of amides I and II appeared in curve A, indicating that there are still some organic remaining in the remains in the thousands of years of burial. Near $1455 \mathrm{~cm}^{-1}$ is the vibration peak of $\mathrm{CO}_{3}{ }^{2-}$, which appears in curves $\mathrm{A}$ and $\mathrm{B}$, but the XRD spectra of the remains before and after ashing only detect the characteristics of $\left(\mathrm{Ca}_{10}\left(\mathrm{PO}_{4}\right) 6(\mathrm{OH})_{2}\right)$, this may be because the characteristic peak of $\mathrm{PO}_{4}{ }^{3-}$ is too strong, which masks the vibration peak of $\mathrm{CO}_{3}{ }^{2-} .873 \mathrm{~cm}^{-1}$ is classified as the contribution of $\mathrm{HPO}_{4}{ }^{2-}$, which is consistent with the small amount of $\mathrm{CaHPO}_{4} \cdot 2 \mathrm{H}_{2} \mathrm{O}$ in fresh bone. All curves have strong and sharp characteristic peaks at $1037 \mathrm{~cm}^{-1}, 564 \mathrm{~cm}^{-1}$ and $604 \mathrm{~cm}^{-1}$, which represent the existence of $\mathrm{PO}_{4}{ }^{3-}$, indicating that even in the underground environment, the composition of the remains is decomposed in a large amount, the inorganic structure is destroyed, which will eventually cause looseness and porosity and decrease in mechanical properties, however, the composition of inorganic minerals has not been changed or contaminated. 


\section{Conclusion}

The contamination of the unearthed human bones by burial environment and diagenesis was judged by using pH measurement, Scanning Electrion Microscopy-Energy Dispersive Spectrometer (SEM-EDS), X-ray Diffraction (XRD), and Fourier transform red external light spectrum (FTIR). The results show that the organic composition of the remains at Shenna ruins is decomposed in a large amount, the inorganic structure is destroyed, which will eventually cause looseness and porosity. However, the composition of inorganic minerals of the human bones has not been changed or contaminated, they could be avoided unnecessary waste of energy and work and research bias in further study of paleoenvironment and paleoclimate in Shenna ruins.

\section{Abbreviations}

SEM-EDS: scanning electrion microscopy-energy dispersive spectrometer, XRD: X-ray diffractiometry, IR: infrared spectra, EDS: energy dispersive spectrometry,

\section{Declarations}

\section{Availability of data and materials}

The datasets used and/or analysis results obtained in the current study are available from the corresponding author on request.

\section{Funding}

The authors gratefully acknowledge the financial support by the National Natural Science Foundation of China (No. 22102094, No. 41601232) and the Fundamental Research Funds for the Central Universities (No. GK 20210361, GK 202103058).

\section{Authors' Contributions}

J. X. L. conceived the research, designed the research methodology, performed experiments, data acquisition and processing, and drafted the manuscript. B. J. M., Y. Z. and L. C. performed the craniofacial measurement and data acquisition and processing. Y. H. L. discussed the results and reviewed and corrected the manuscript. J. L. W. and J. C. designed the research methodology, conducted data analysis, and revised the manuscript. Y. H. L., J. L. W. and J. C. have contributed equally to this work.

\section{Competing interests}

The authors declare no competing financial interests.

Conflict of interest 
The authors declare that they have no conflicts of interest related to this work. We declare that we do not have any commercial or associative interest that represents a conflict of interest in connection with this work submitted.

\section{References}

1. Szostek K, Głąb H, Pudło A. The use of strontium and barium analyses for the reconstruction of the diet of the early medieval coastal population of Gdańsk (Poland): A preliminary study. HOMO Journal of Comparative Human Biology, 2009; 60(4). https://doi.org/10.1016/j.jchb.2009.01.001.

2. Xuelian Z. Analyses of $13 \mathrm{C}$ and $15 \mathrm{~N}$ and the New Perspectives on Ancient Diet. Chinese Archaeology, 2007; 7(1). https://doi.org/10.1515/CHAR.2007.7.1.188.

3. JPB MD, PL MSc, MM MSc, RO PhD, CP PhD, JPW MD, et al. Palatine Sutures as Age Indicator: A Controlled Study in the Elderly. J Forensic Sci, 2010; 55(1). https://doi.org/10.1111/j.15564029.2009.01237.x.

4. Rougé-Maillart C, Vielle B, Jousset N, Chappard D, Telmon N, Cunha E. Development of a method to estimate skeletal age at death in adults using the acetabulum and the auricular surface on a Portuguese population. Forensic Sci Int, 2009; 188(1). https://doi.org/10.1016/j.forsciint.2009.03.019.

5. Cameriere R, Bestetti F, Palacio LAV, Riccomi G, Skrami E, Parente V, et al. Carpals and epiphyses of radius and ulna as age indicators using longitudinal data: a Bayesian approach. Springer Berlin Heidelberg, 2019; 133(1). https://doi.org/10.1007/s00414-018-1807-7.

6. Kontopoulos I, Nystrom P, White L. Experimental taphonomy: post-mortem microstructural modifications in Sus scrofa domesticus bone. Forensic Sci Int. 2016;266:320-8. https://doi.org/10.1016/j.forsciint.2016.06.024.

7. Cappella A, Gibelli D, Muccino E, Scarpulla V, Cerutti E, Caruso V, et al. The comparative performance of PMI estimation in skeletal remains by three methods (C-14, luminol test and $\mathrm{OHI}$ ): analysis of 20 cases. Int J Legal Med, 2018; 132(4). https://doi.org/10.1007/s00414-015-1152-z.

8. Hedges R. Bone diagenesis: an overview of processes. Archaeometry, 2002; 44(3). https://doi.org/10.1111/1475-4754.00064.

9. Stathopoulou ET, Psycharis V, Chryssikos GD, Gionis V, Theodorou G. Bone diagenesis: New data from infrared spectroscopy and X-ray diffraction. Palaeogeography Palaeoclimatology Palaeoecology. 2012;266(3):168-74. https://doi.org/10.1016/j.palaeo.2008.03.022.

10. Hu Y, Wang C, Zuo J, et al. XRD and Raman spetra of hydroxylapatite in ancient human bones. Acta Biophys Sin (in Chinese). 2001;17(4):621-7. https://doi:CNKI:SUN:SWWL.0.2001-04-002.

11. János I, Szathmáry L, Nádas E, Béni A, Dinya Z, Máthé E. Evaluation of elemental status of ancient human bone samples from Northeastern Hungary dated to the 10th century AD by XRF. Nuclear Inst Methods in Physics Research B, 2011; 269(21). https://doi.org/10.1016/j.nimb.2011.07.016. 
12. Li J, Qu RM, Dai JX, Zhou ZT, Yuan L. Mechanical and physicochemical properties of xenogeneic bone scaffold materials: A comparative study. Journal of Clinical Rehabilitative Tissue Engineering Research, 2008; 12(45): 8931-8934. https://doi:CNKI:SUN:XDKF.0.2008-45-049.

13. Hu Y, Wang C, Zuo J, et al. XRD and Raman spetra of hydroxylapatite in ancient human bones. Acta Biophys Sin (in Chinese). 2001;17(4):621-7. https://doi:CNKI:SUN:SWWL.0.2001-04-002.

14. Loukopoulou M, Pentzou-Daponte A. A craniofacial morphological study of a population of northern Greek children. Int J Anthropol. 1995;10:133-42. https://doi.org/10.1007/BF02444604.

15. Wu X, Liu W, Zhang Q, et al. Craniofacial morphological microevolution of Holocene populations in northern China. CHINESE SCI BULL. 2007;52:1661-8. https://doi.org/10.1007/s11434-007-0227-8.

16. Akkus $\mathrm{O}$, Jepsen KJ, Rimnac CM. Microstructural aspects of the fracture process in human cortical bone. Journal of Materials Science. 2000;35:6065-74. https://doi.org/10.1023/A:1026719531300.

17. Figueiredo M, Fernando A, Martins G, Freitas J, Judas F, Figueiredo H. Effect of the calcination temperature on the composition and microstructure of hydroxyapatite derived from human and animal bone. Ceram Int. 2010;36(8):2383-93. https://doi.org/10.1016/j.ceramint.2010.07.016.

18. Lebon M, Reiche I, Bahain J, Chadefaux C, Moigne AM, Fröhlich F, Sémah F, Schwarcz HP, Falguères C. New parameters for the characterization of diagenetic alterations and heat-induced changes of fossil bone mineral using Fourier transform infrared spectrometry. J. Archaeol. 2010; Sci., 37(9), 2265-2276. https://doi.org/10.1016/j.jas.2010.03.024.

19. A CLK, B NT, C KCG. Re-examining the chemical evaluation of diagenesis in human bone apatite. Journal of Archaeological Science, 2011; 38(9):22222230. https://doi.org/10.1016/j.jas.2011.03.023.

20. Bigi A, Cojazzi G, Panzavolta S, Ripamonti A, Moro L. Chemical and structural characterization of the mineral phase from cortical and trabecular bone. J Inorg Biochem. 1997;68(1):4551. https://doi.org/10.1016/S0162-0134(97)00007-X.

21. Rey C, Collins B, GoehI T, Dickson IR, Glimcher MJ. The carbonate environment in bone mineral: A resolution-enhanced fourier transform infrared spectroscopy study. Calcif Tissue Int. 1989;45(3):157-64. https://doi.org/10.1007/BF02556059.

22. Paschalis EP, Dicarlo E, Betts F, Sherman P, Mendelsohn R, Boskey AL. FTIR microspectroscopic analysis of human osteonal bone. Calcif Tissue Int. 1996;59(6):4807. https://doi.org/10.1007/BF00369214.

23. Beasley MM, Bartelink EJ, Taylor L, Miller RM. Comparison of transmission FTIR, ATR, and DRIFT spectra: implications for assessment of bone bioapatite diagenesis. J Archaeol Sci. 2014;46:1622. https://doi.org/10.1016/j.jas.2014.03.008.

24. Lee-Thorp J, Sponheimer M. Three case studies used to reassess the reliability of fossil bone and enamel isotope signals for paleodietary studies. J Anthropol Archaeol. 2003;22(3):20816. https://doi.org/10.1016/S0278-4165(03)00035-7.

25. Garvie-Lok SJ, Varney TL, Katzenberg MA. Preparation of bone carbonate for stable isotope analysis: the effects of treatment time and acid concentration. J Archaeol Sci. 2004;31(6):763- 
76. https://doi.org/10.1016/j.jas.2003.10.014.

\section{Figures}

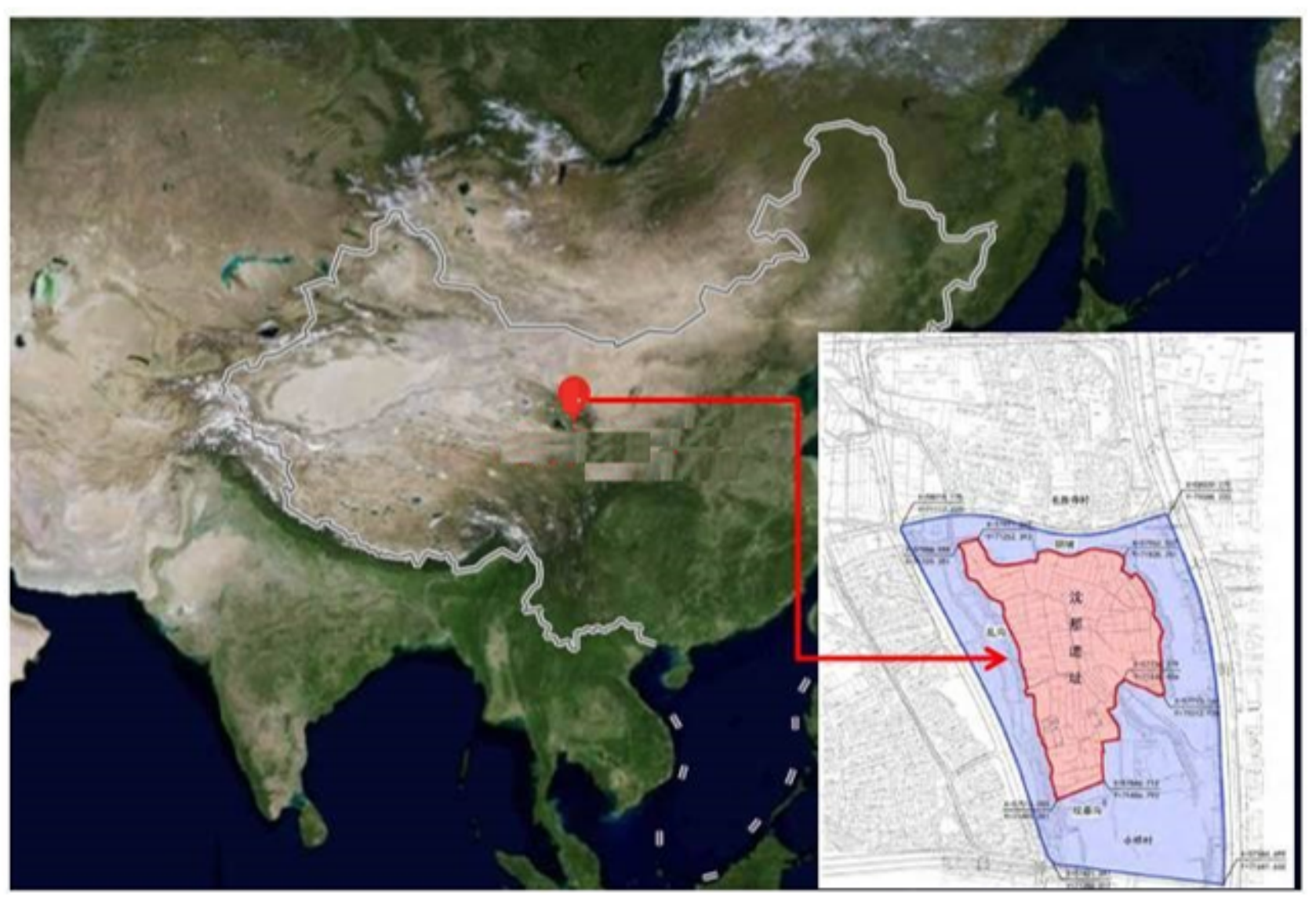

Figure 1

Location map of Shenna ruins, China

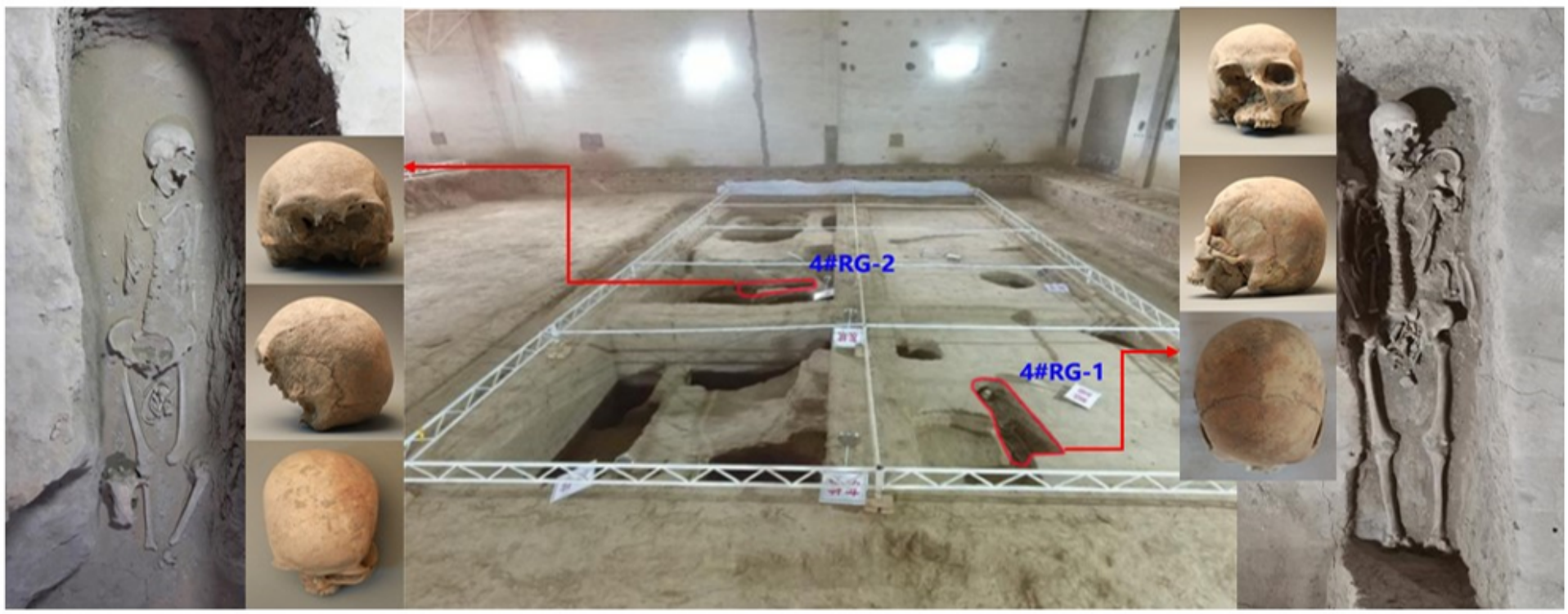

Figure 2 
The excavation location and the frontal view, side view and top view of RG1 and RG2 skull
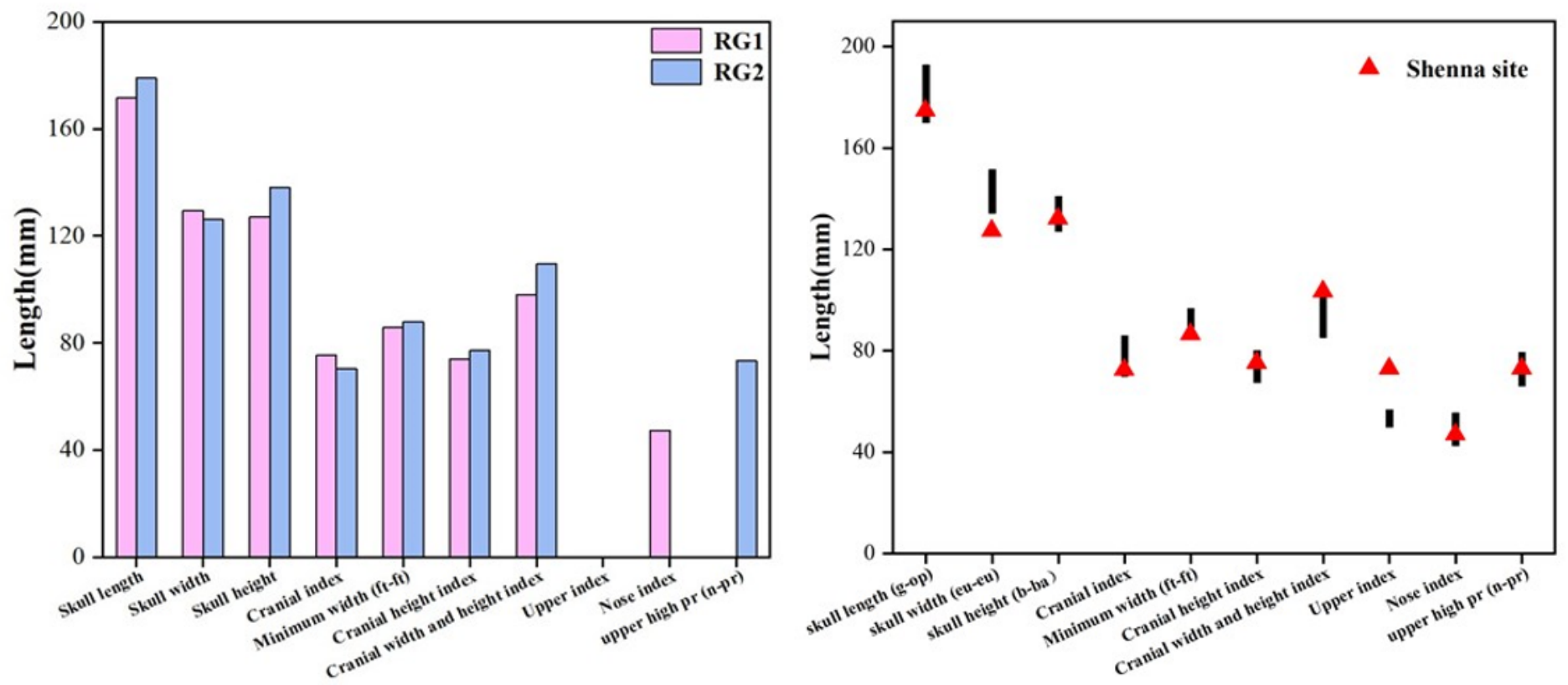

Figure 3

Comparison of measurement data of RG1 and RG2 skull (left) and the characteristics of human bones at Shenna ruins compared with those of Asian Mongolians (right) 


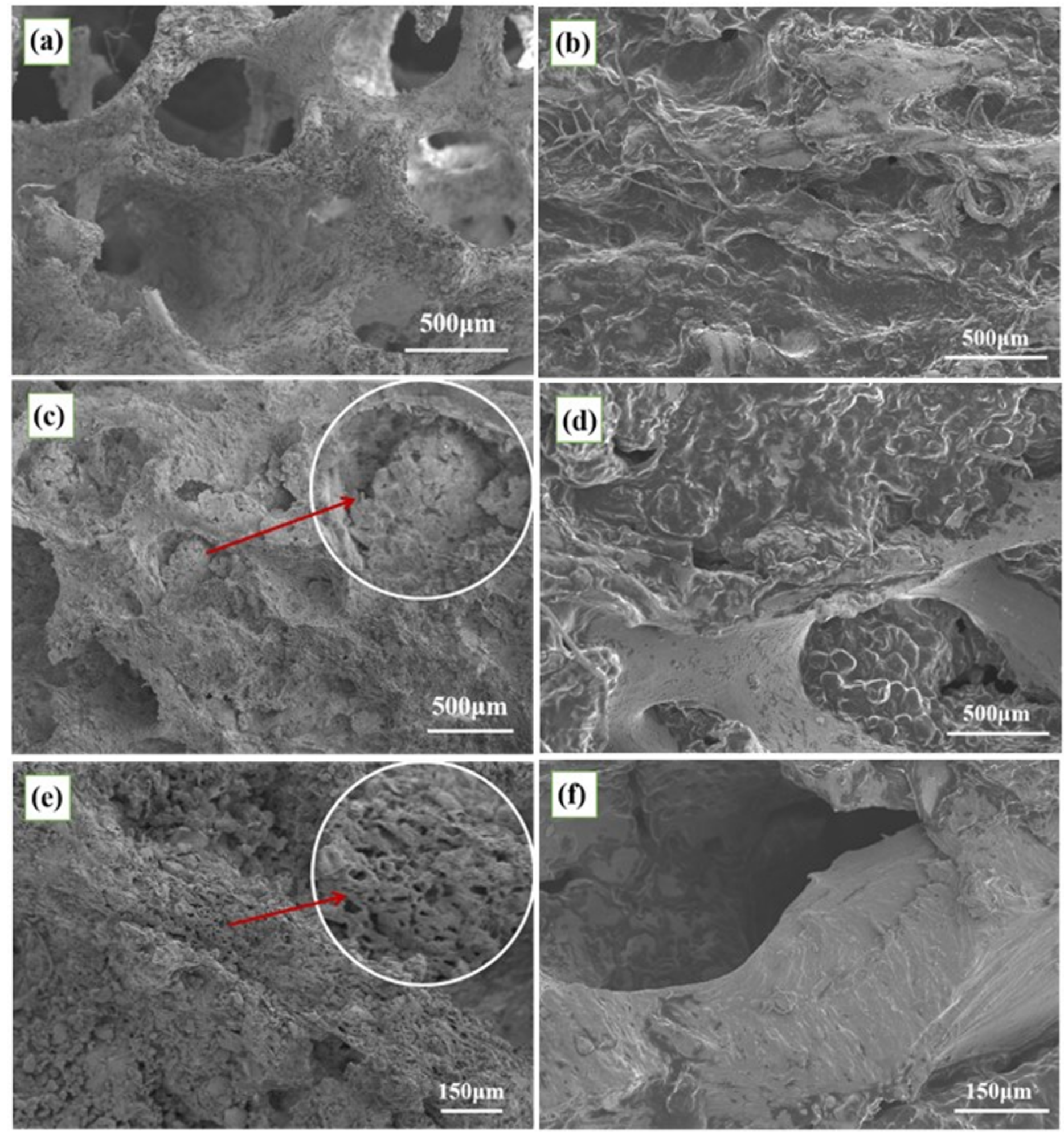

Figure 4

Comparison of the microscopic morphologies of the remains $(a, c, e)$ and modern pig bones $(b, d, f)$ 

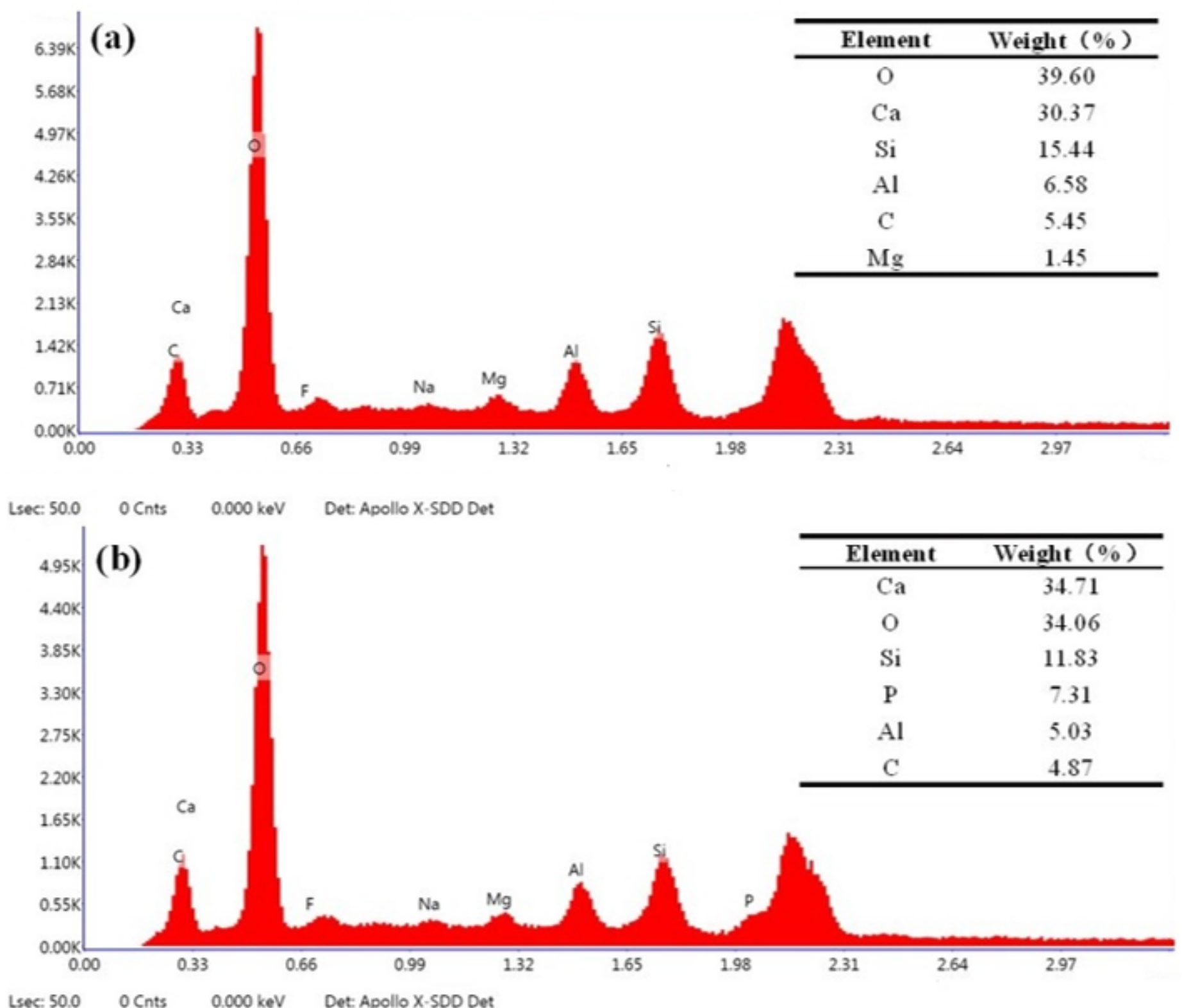

\section{Figure 5}

Element distribution of soil and remains (a: soil; b: remains) 

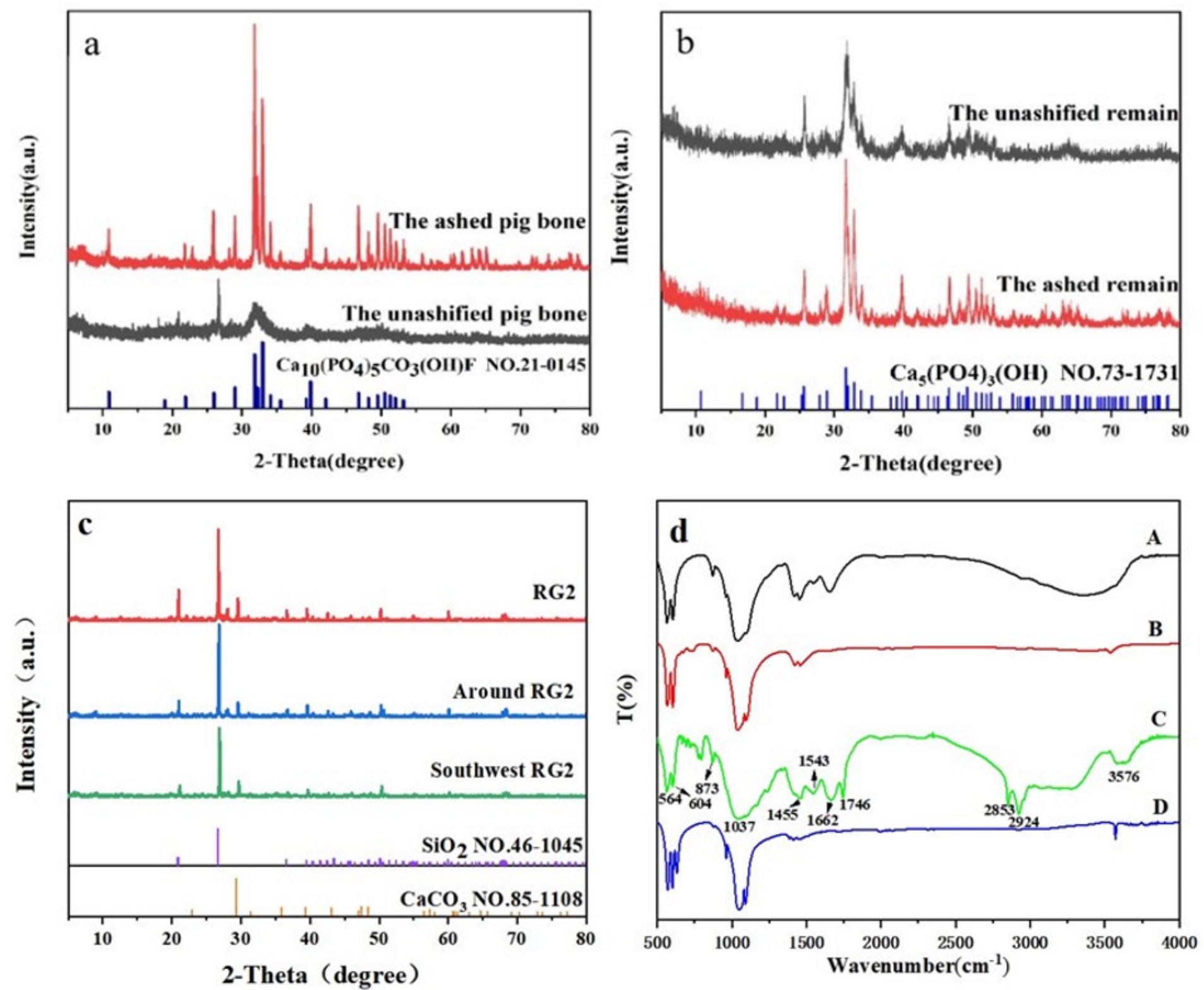

Figure 6

XRD comparison between pig bone (a), remains (b) andsoil (c) before and after ashes, and the infrared spectra (IR) of the remains (A, B) and pig bones (C, D) before and after ashing. 